\title{
ENTRE DOCUMENTOS E REPRESENTAÇÕES: REFLEXÕES SOBRE A OPERAÇÃO HISTORIOGGRÁFICA NA REVISTA PAIS \& FILHOS
}

\author{
Liana Pereira Borba dos Santos ${ }^{1}$ \\ lattes.cnpq.br/0712023089149536
}

\begin{abstract}
Resumo: O objetivo desse artigo é discutir, à luz da história cultural, elementos relevantes para a construção de uma operação historiográfica, como a metodologia, a escolha e o uso das fontes, assim como a sua respectiva materialidade. Trata-se de um processo que se consolida, de um lado, na escrita de uma narrativa autoral e, de outro, na aproximação com os demais estudos do campo científico. De modo específico, pretende-se estabelecer um diálogo entre os discursos teóricos e metodológicos com a pesquisa desenvolvida, no qual realizo o levantamento e análise das práticas discursivas e representações sociais de infância e de suas instituições afins (como famílias, espaços escolares e médicos, por exemplo), nas páginas da revista Pais \& Fïlhos.
\end{abstract}

Palavras-chave: Operação Historiográfica; História Cultural; Revista Pais \& Filhos; Educação.

\section{BETWEEN DOCUMENTS AND REPRESENTATIONS: REFLECTIONS ON THE HISTORIOGRAPHICAL OPERATION IN THE PAIS \& FILHOS MAGAZINE}

\begin{abstract}
This present paper aims to discuss the prominent issues for the historiographical operation in the context of cultural history, as the methodology, the choice and use of sources and their respective materiality. On the one hand, this process is consolidated in writing an authorial narrative and the other hand it is marked by the necessary approximation with other studies the scientific field. In a specific way, the goal is to relate the theoretical and methodological discourse to the research that I have developed, in which I realize the analysis of the discursive practices and social representations of childhood and its related institutions (such as families, school spaces and doctors, for example), the pages of the publication entitled Pais \& Filhos (Parents \& Children).
\end{abstract}

Keywords: Historiographical operation; Cultural history; Pais \& Filhos Magazine; Education

\footnotetext{
${ }^{1}$ Doutoranda em Educação pela Universidade do Estado do Rio de Janeiro (Brasil). Contato: lianaborba@gmail.com.
} 


\title{
O campo de estudos da história cultural
}

Como se define o campo de estudos da história cultural? Uma resposta categórica não é fácil. Pode-se dizer que história cultural corresponde a um movimento de reação deliberada ao paradigma dito tradicional, de ancoragem positivista. Nessa perspectiva, a história é, essencialmente, uma narrativa dos acontecimentos. A história cultural, por sua vez, tem como base filosófica a ideia de que a realidade é social e culturalmente constituída. Nesse sentido, faz-se necessário problematizar o próprio objeto da ciência histórica: os seus documentos.

Para Le Goff (1986), os fundadores da revista Annales d'histoire économique et sociale podem ser considerados pioneiros de uma nova historiografia, visto que insistiram sobre a necessidade de ampliar a noção de documento. Para eles:

\begin{abstract}
A história se faz com documentos escritos, sem dúvida. Quando estes existem. Mas pode fazer-se, deve fazer-se sem documentos escritos, quando não existem. Com tudo o que a habilidade do historiador lhe permite utilizar para fabricar o seu mel, na falta das flores habituais. Logo, com palavras. Signos. Paisagens e telhas. Com as formas do campo e das ervas daninhas. Com os eclipses da lua e a atrelagem de cavalos de tiro. Com os exames de pedras feitos pelos geólogos e com as análises de metais feitas pelos químicos. Numa palavra, com tudo o que, pertencendo ao homem, depende do homem, serve o homem, exprime o homem, demonstra a presença, a atividade, os gostos as maneiras do ser e do homem (LE GOFF, 1986, p. 98).
\end{abstract}

Le Goff sugere, ainda, a ampliação do sentido do documento escrito, contemplando também elementos sonoros, pictóricos, indumentárias, entre outros, pois os problemas históricos não correspondem a apenas um tipo único de documentos.

A partir dos anos 1960, também emerge uma revolução documental, pautada em fundamentos qualitativos e quantitativos, em que a escrita da história e da memória coletiva já não se baseia exclusivamente nos grandes homens, nos acontecimentos, na história que avança depressa, na história política, diplomática ou militar. Ao contrário, interessa-se por 
todos os homens, considerados por Bloch (2001) como objetos da história, por natureza: "Por trás dos escritos aparentemente mais insípidos e as instituições aparentemente mais desligadas daqueles que a criaram, são os homens que a história quer capturar" (BLOCH, 2001, p. 54).

Tal revolução documental propõe, ainda, um corte epistemológico: em lugar do fato que conduz ao acontecimento, considerado linear, temos o dado, que leva à série e possibilita uma histórica descontínua. A concepção de documento/monumento colabora com essa reflexão, compreendido como o poder da escolha do documento, de sua valorização, capaz de transformar e monumentalizar o documento:

A concepção do documento/monumento é, pois, independente da revolução documental e entre os seus objetivos está o de evitar que esta revolução necessária se transforme num derivativo e desvie o historiador do seu dever principal: a crítica do documento - qualquer que ele seja - enquanto monumento. O documento não é qualquer coisa que fica por conta do passado. É um produto da sociedade que o fabricou, segundo as relações de força, que aí, detinham o poder (LE GOFF, 1985, p. 102).

Aqui, o documento é monumento, pois resulta do esforço das sociedades históricas para impor ao futuro - voluntária ou involuntariamente - determinada imagem de si próprias. A nova compreensão de documento, transformado em dado, otimiza a construção de uma história quantitativa, devendo ser tratado como documento/monumento.

Burke (1992), por sua vez, chama atenção para os desafios vividos pelo historiador, mostrando como ele faz parte da história:

Os historiadores estão tendo de se preocupar com questões que por muito tempo interessaram a sociólogos e a outros cientistas sociais. Quem são os verdadeiros agentes na história, os indivíduos ou os grupos? Será que eles podem resistir com sucesso às pressões das estruturas sociais, políticas ou culturais? São essas estruturas meramente restrições à liberdade de ação, ou permitem aos agentes realizarem mais escolhas? (BURKE, 1992, p. $31)$.

Este cruzamento de fronteiras entre áreas de conhecimento, vivenciado no campo da história, é abordado por Bloch, em sua obra Apologia da História (2001). O intelectual indica a existência de uma tensão epis- 
temológica com o campo da sociologia, em que parece ocorrer uma segmentação dos fatos sociais. Sua questão fundamental está ancorada na própria ideia de que se faz do passado e na compreensão de que se pode fazer dele uma ciência.

Roger Chartier (2002) indica que a partir da crítica recebida pela história no contexto de 1960-1970, motivada pela grande ênfase dada aos estudos de objetos marcados pela exploração do econômico e do social, em meio à crise das ciências sociais, os próprios historiadores encontraram um novo caminho investigativo: captar objetos de análise já apontados por outros campos. No entanto, merece atenção o fato de que, atualmente, o campo historiográfico enfrenta novos desafios:

Ele não se ancora mais em uma crítica dos hábitos da disciplina em nome das ciências sociais, mas um uma crítica dos postulados das próprias ciências sociais. Os fundamentos intelectuais da ofensiva são claros: de um lado, o retorno a uma filosofia do sujeito que recusa a força das determinações coletivas e dos condicionamentos sociais e que pretende reabilitar a parte explícita e refletida da ação; de outro, a primazia concedida ao político que supostamente constitui o nível mais globalizante da organização das sociedades, e, para isso, fornece uma nova chamada para a arquitetura da totalidade (CHARTIER, 2002, p. 64).

Chartier sugere algumas inflexões para explicar a transformação do campo historiográfico dos últimos anos, que fogem à explicação formulada sobre uma dita "crise das ciências sociais" ou uma "mudança de paradigma”. Na verdade, estariam ligadas "à distância tomada, nas próprias práticas de pesquisa, em relação aos princípios de inteligibilidade que haviam governado o método histórico nos últimos vinte ou trinta anos” (CHARTIER, 2002, p. 64).

Com isso, podemos compreender que a nova historiografia critica a diferenciação social prévia em que se credita a possibilidade de demarcar, a priori, as produções culturais. Podemos, ainda, atentar para o fato de que essa nova perspectiva se mostra aberta para pensar "outros modos de articulação entre as obras ou as práticas, estando sensível, ao mesmo tempo, à pluralidade das clivagens que atravessam a sociedade e à diver- 
sidade dos empregos de materiais ou de códigos partilhados” (CHARTIER, 2002, p. 76).

Biccas (2012) aproxima-se dos estudos de Chartier para afirmar que a nova história cultural corresponde "ao estudo dos processos com os quais os sujeitos constroem sentidos para as suas ações” (BICCAS, 2012, p. 285), não se tratando de uma história das ideias, tampouco de uma história intelectual e cultural. Centra-se, pois, na compreensão dos sentidos que os sujeitos dão a seus mundos e existências, na relação, mas não na submissão aos condicionantes que enfrentam. Daí a importância, nesse contexto, "de noções de prática, sentido, significado, representação, costume, apropriação, entre tantas outras” (BICCAS, 2012, p. 284).

No caso específico da investigação empreendida por mim no doutoramento, fundamentada no levantamento e na análise de representações sociais acerca da infância divulgadas na revista mensal Pais \& Filhos, aproximo-me do campo da história cultural, por considerar que a mesma propõe "um espaço de trabalho entre textos e leituras, no intuito de compreender as práticas, complexas, múltiplas, diferenciadas, que constroem o mundo como representação" (CHARTIER, 1990, p. 28).

No que diz respeito ao estudo das representações do mundo social, Chartier (1990) aponta que elas são construídas em um dado espaço, por um dado grupo. Por isso, para cada caso, faz-se necessário relacionar os discursos proferidos e a posição de quem os enuncia. É relevante compreender que as formas de compreensão do social não são discursos neutros, e sim construtores de estratégias e práticas (sociais, escolares, políticas) que tendem a impor certa autoridade à custa de outros, a legitimar um projeto reformador ou a justificar, para os próprios indivíduos, as suas escolhas e condutas (CHARTIER, 2002).

Na perspectiva da história cultural, o conceito de representação pode ser compreendido como:

Instrumento de um conhecimento mediato, que faz ver um objeto ausente através de sua substituição por uma imagem capaz se o reconstruir em memória e de figurá-lo tal como ele é. [...]. Uma relação compreensível é, então, postulada entre o signo visível e o referente por ele significado - o que não quer dizer que 
seja necessariamente estável e unívoca (CHARTIER, 1990, p. 20).

Pode-se, ainda, apontar três modalidades da relação com o mundo social, ou três realidades observáveis da representação:

a) o trabalho de classificação e de recorte que produz as configurações intelectuais múltiplas pelas quais a sociedade é contraditoriamente construída pelos diferentes grupos que compõe a sociedade;

b) as práticas que visam reconhecer uma identidade social, a exibir uma maneira própria de estar no mundo, a significar simbolicamente um estatuto e uma posição;

c) as formas institucionalizadas e objetivadas, graças as quais "representantes" (instâncias coletivas ou indivíduos singulares) marcam de modo visível e perpetuado a existência do grupo, da comunidade ou da classe (CHARTIER, 2002, p. 73).

O processo de levantamento e análise das representações sociais, contemplando suas multiplicidades de olhares, permite perceber que as diferenciações culturais são processos dinâmicos. As representações do mundo social construídas nesse contexto, embora visem à universalidade de um diagnóstico pautado na razão, são, em grande medida, determinadas pelos interesses do grupo que as forjam. É por isso que, para cada caso, faz-se necessário relacionar os discursos proferidos e a posição de quem os utiliza.

\section{Fazer com: questões e fontes}

A história, como ciência, possui uma estética própria de linguagem. No campo historiográfico, os indícios são elementos relevantes, mas uma ciência não se define apenas por seu objeto. Seus limites podem ser fixados, também, pela natureza própria de seus métodos. Cabe ao historiador ser capaz de tratar os fatos históricos, com uma sensibilidade artística, metaforizada pela figura do luthier (BLOCH, 2001, p. 76). Então, como se constitui o método historiográfico, considerando, de antemão, a dinâmica da escolha e construção de seus documentos? 
Prost (2008) discute a centralidade da postulação da questão para a história, que serve de fundamento e contribui para a construção do objeto histórico. A questão permite construir fatos e pressupõe que o historiador vislumbre as fontes e os documentos que permitirão sua resolução. Para Prost, não há questão sem documentos, mas o autor indica, por outro lado, a relevância de um primado da questão sobre o documento, que implica a) na impossibilidade da leitura definitiva do documento; b) na renovação da questão; c) na ampliação e renovação documental e de seus métodos de análise (PROST, 2008, p. 76).

À luz da história cultural, deve-se evitar cair na armadilha de uma supervalorização do documento ou da questão. Para tal, entende-se que ambos devem ser pensados em uma inter-relação, pois ainda que o pesquisador proponha, inicialmente, sua questão problema, é no contato com as fontes que a fluidez do trabalho se torna possível. As questões se tornam complexas, visto que englobam um olhar minucioso sobre as fontes. Sendo assim, "a pesquisa é indefinidamente relançada” (PROST, 2008, p. 79), reforçando a instabilidade e abertura de seu percurso.

Bacellar (2005) também propõe uma reflexão sobre o estabelecimento das questões na pesquisa histórica, produzidas pelo historiador e consideradas como os elementos definidores da natureza da pesquisa. $\mathrm{O}$ autor se aproxima das colocações de Prost ao compreender que a concepção de uma questão traz em seu bojo os documentos como fontes. Marca, ainda, a existência de solidariedade entre a questão, os documentos e os procedimentos, um tripé que mobiliza o pesquisador e possibilita a formulação da interpretação própria do sujeito: "A história não é opinião subjetiva, ela situa-se entre o mais subjetivo e o mais objetivo" (BACELLAR, 2005, p. 93). Profundamente enraizada na personalidade de seu formulador, ela se constitui apenas se for concordante com documentos em que possa encontrar respostas.

O tempo da história e a temporalidade moderna se constituem como "realidade viva e concreta, submetida à irreversibilidade de seu impulso" (BLOCH, 2001, p. 55). O tempo, nesse sentido, configura como um problema, já que "o tempo verdadeiro é, por natureza, um continuum. É também perpétua mudança. Da antítese desses dois atributos 
provêm os grandes problemas da pesquisa histórica” ( $\mathrm{BLOCH}, 2001$, p. 55). Assim, o historiador deve vivenciar o contato com o tempo social, como referência comum aos membros de um grupo, permeado por questões, documentos e fatos.

Por outro lado, considerar o elemento tempo na pesquisa histórica exige que o historiador perceba a impossibilidade de ele próprio constatar os fatos que estuda. Bloch ressalta a impossibilidade da total aproximação do contexto observado, ainda mais se levarmos em conta que "toda coletânea de coisas vistas é, em uma boa metade, coisas vistas por outro" (BLOCH, 2001, p. 70). Não se conhece a situação dos sujeitos observados senão "por meio do panorama que eles mesmos aceitam me fornecer. Porque no imenso tecido de acontecimentos, gestos e palavras de que se compõe o destino de um grupo humano, o indivíduo percebe apenas um cantinho, estreitamente limitado por seus sentidos e sua faculdade de atenção" (BLOCH, 2001, p. 70).

Com base nas abordagens teóricas discutidas até o momento, percebe-se que a abordagem metodológica, a escolha e o manuseio das fontes assumem papel de destaque. Na pesquisa desenvolvida, propõe-se uma análise histórica e documental da revista mensal Pais \& Filhos, corpus documental tratado como fonte e como objeto de investigação. Chartier colabora com a reflexão, ao indicar que as fontes utilizadas pela pesquisa historiográfica não têm sentido estável, universal e cristalizado, pois são investidas de "significações plurais e móveis, construídas da negociação entre uma proposição e uma recepção, no encontro entre formas e motivos que lhe dão sua estrutura e as competências ou expectativas dos públicos que delas se apoderam” (CHARTIER, 1990, p. 103).

\section{Por dentro da fonte - um olhar sobre a revista Pais \& Filhos}

A publicação, utilizada como fonte e objeto de pesquisa neste artigo, foi lançada em setembro de 1968 e teve como seu idealizador e primeiro diretor Adolpho Bloch, sendo atualmente produzida pela Editora 
Manchete, caracterizando-se como uma das publicações periódicas de maior longevidade do mercado brasileiro ${ }^{2}$.

Os aspectos pertinentes à materialidade da fonte também merecem

Figura 1 - Capa do exemplar n. 1 de Pais \& Filhos.

Fonte: Fundação Biblioteca Nacional Pais \& Filhos, set. 1968, n. 1, p. 1.

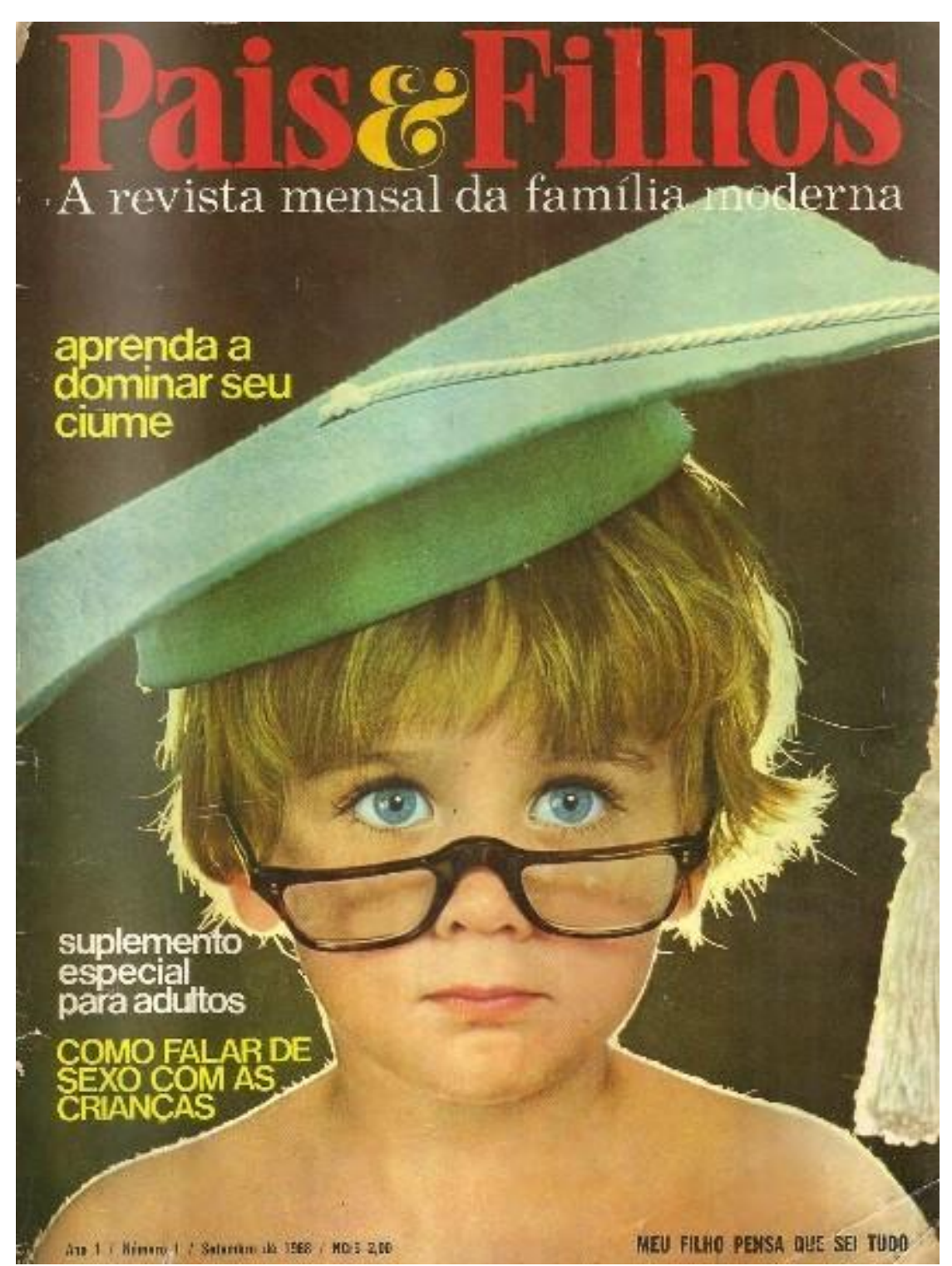

destaque. A partir da leitura de Chartier, pode-se dizer que ela se fundamenta na análise da produção de textos, atentando para as possibilidades de leitura e interpretação que seu suporte permite. A forma também é considerada como elemento constitutivo de sentido para a leitura crítica do impresso. Tal afirmação serve de alerta aos pesquisadores da leitura e da história do impresso, especialmente no que diz respeito ao fato de que "as formas dadas a ler, a ouvir ou a ver os

textos participam da construção de significados” (BICCAS, 2012, p. 287).

\footnotetext{
2 O estudo de Mira (2001) sobre a imprensa periódica no Brasil colaborou com esta reflexão e possibilitou a compreensão da década de 1960 como um período de grande otimização do mercado do impresso. A autora levantou resultados da pesquisa do IBOPE realizada em 1969 e verificou a efervescência de uma variedade de publicações semanais, quinzenais e mensais, destacando a presença da revista Pais \& Filhos no primeiro lugar no ranking de revistas mensais (MIRA, 2001, p. 61).
} 
No caso deste trabalho, faz-se necessário elucidar como se efetua o manuseio e o tratamento da fonte-objeto investigada. A consulta ao acervo de Pais \& Fïlhos é realizada na Fundação Biblioteca Nacional (FBN), localizada na cidade do Rio de Janeiro, com exemplares em formato original3.

Figura 2 - Coleção encadernada. Fonte: Fundação Biblioteca Nacional - Pais \& Filhos, coleção jul./dez. 1969.

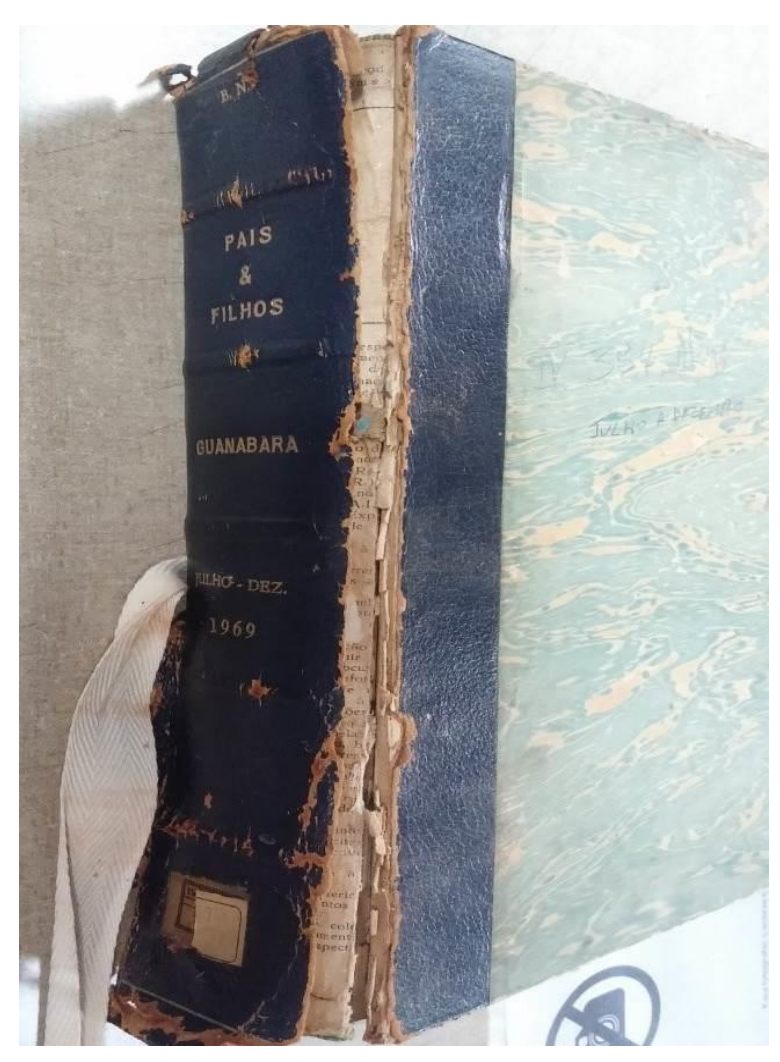

Figura 3 - Coleção avulsa. Fonte: Fundação Biblioteca Nacional - Pais \& Filhos, coleção jul./dez. 1975.

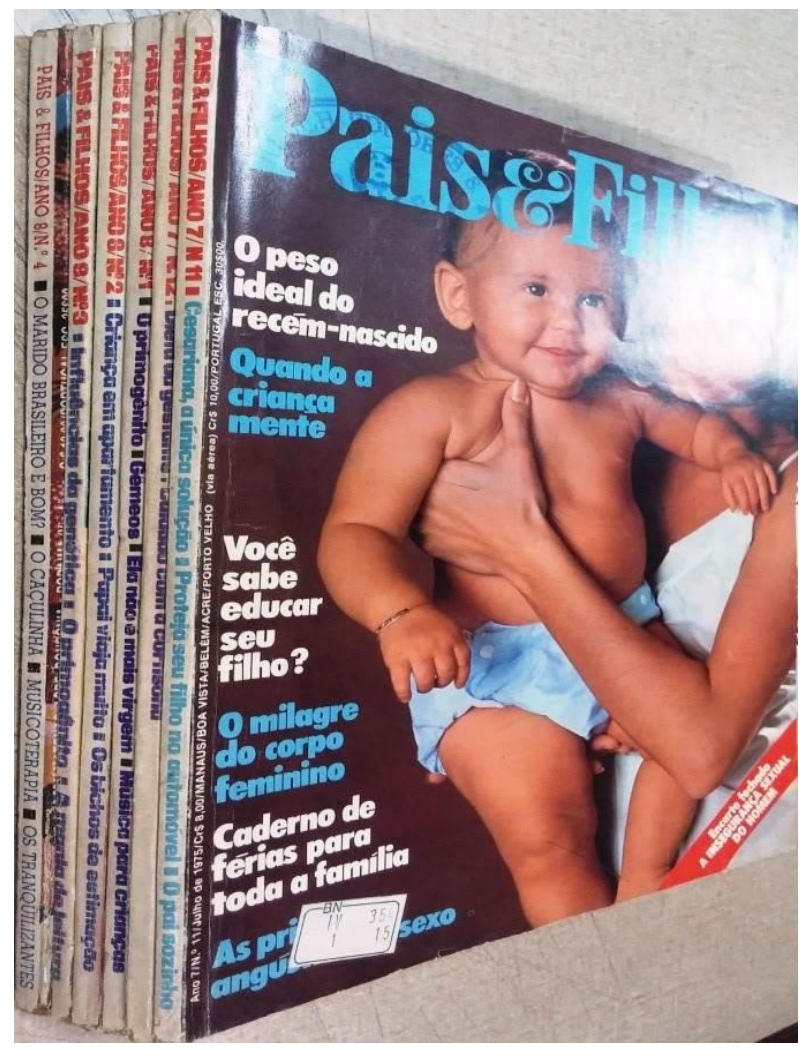

Algumas coleções foram encadernadas e outras estão soltas em pastas. Tal distinção potencializa o olhar sobre a fonte, exemplificada pelo fato de que, nos exemplares avulsos, é possível atentar para detalhes presentes nas lombadas, como títulos de matérias de destaque no exemplar, assim como ler informações relativas ao preço e ao ano, impressas no

\footnotetext{
3 A Biblioteca Nacional possui o acervo impresso de Pais \& Filhos de janeiro de 1969 a agosto de 2010. Os exemplares de 1968, não disponíveis na Biblioteca, puderam ser analisados por meio do acesso ao sistema colaborativo Issuu: a) Revista Pais \& Filhos, n. 1, set. 1968. (http://issuu.com/ arquivopaisefilhos/docs/revistapaisefilhosnumero1); b) Revista Pais \& Filhos, n. 4, dez. 1968. (http://issuu.com/ arquivopaisefilhos/docs/revistapaisefilhosnumero4).
} 
canto esquerdo. Já na coleção encadernada, essas informações não ficam visíveis.

Levando em conta a extensão do quantitativo de volumes de Pais \& Filhos disponíveis para consulta na FBN, foi necessário estabelecer alguns recortes ou marcos temporais para a análise. Prost (2008) elucida esse elemento constitutivo da operação historiográfica, apresentando uma proposta de trabalho sobre o tempo, em que se faz necessário classificar os acontecimentos e estabelecer uma periodização, devido à necessidade de análise, em que "o fazer histórico recorta o tempo para melhor estudá-lo” (Prost, 2008, 108). A periodização permite pensar, a um só tempo, continuidade e ruptura.

Nos primeiros contatos com Pais \& Filhos, fez-se necessário tomar conhecimento da própria história da revista. O periódico foi publicado pela Bloch Editores S.A. até dezembro de 2001. No ano de 2000, a empresa declarou falência e sua massa falida foi comprada, em 2002, pelo empresário Marcos Dvoskin, que criou a Editora Manchete. Em 2003, a nova editora retomou a publicação de Pais \& Filhos, que segue até os dias atuais. Tal situação mobilizou a opção pela análise dos exemplares do ano 1968 até o ano 2001, período em que a revista estava nas mãos da Editora Bloch.

Diante da impossibilidade de analisar a totalidade de exemplares publicados no período em que a revista circulou pela Editora Bloch, estabeleceu-se a amostra de dois volumes por ano, contemplando a edição do primeiro semestre e uma do segundo semestre. Essa opção se baseou nas observações feitas a partir de uma análise preliminar da revista, em que se constatou que os exemplares de janeiro e fevereiro, em grande medida, traziam artigos sobre a relação das crianças e das famílias com o retorno às aulas. Já nas edições de setembro, mês do aniversário da publicação, as revistas apresentavam informações relevantes a respeito de sua própria história, assim como sobre o cenário social do período pesquisado.

A periodização estabelecida pretendeu, ainda, oferecer um olhar sobre as publicações ao longo do período, a fim de identificar as possíveis transformações ou permanências experimentadas pela revista nas décadas de 1970, 1980, 1990 e 2000. Algumas mudanças podem ser mais fa- 
cilmente observadas, como aquelas experimentadas na apresentação dos sumários. Como exemplo, destaca-se que, em 1969, vemos uma lista simples com os títulos dos artigos. Em janeiro de 1974, observa-se o uso de imagens, acompanhadas de breves releases dos artigos em destaque. Já na edição de abril do mesmo ano, encontramos a organização dos assuntos em categorias como: família, criança e gravidez. A especialização dos assuntos pode servir de indício da concomitante segmentação do discurso sobre a infância, como se percebe na edição de 1989, em que apresenta uma ampliação de eixos temáticos e a segmentação da infância em períodos etários, como: recém-nascido, 1-3 anos, 3-5 anos, 7-10 anos e adolescentes.

No que diz respeito ao modo de operar com a fonte/objeto, primeiramente, efetua-se o registro das informações catalográficas (número, ano, preço de venda, número de páginas) e em seguida, o sumário. É importante ainda o registro da equipe editorial e das informações relativas à circulação da revista.

Figura 4 - Informações de circulação.

Fonte: Fundação Biblioteca Nacional - Pais \& Filhos, set. 1970, n. 1, p. 178.

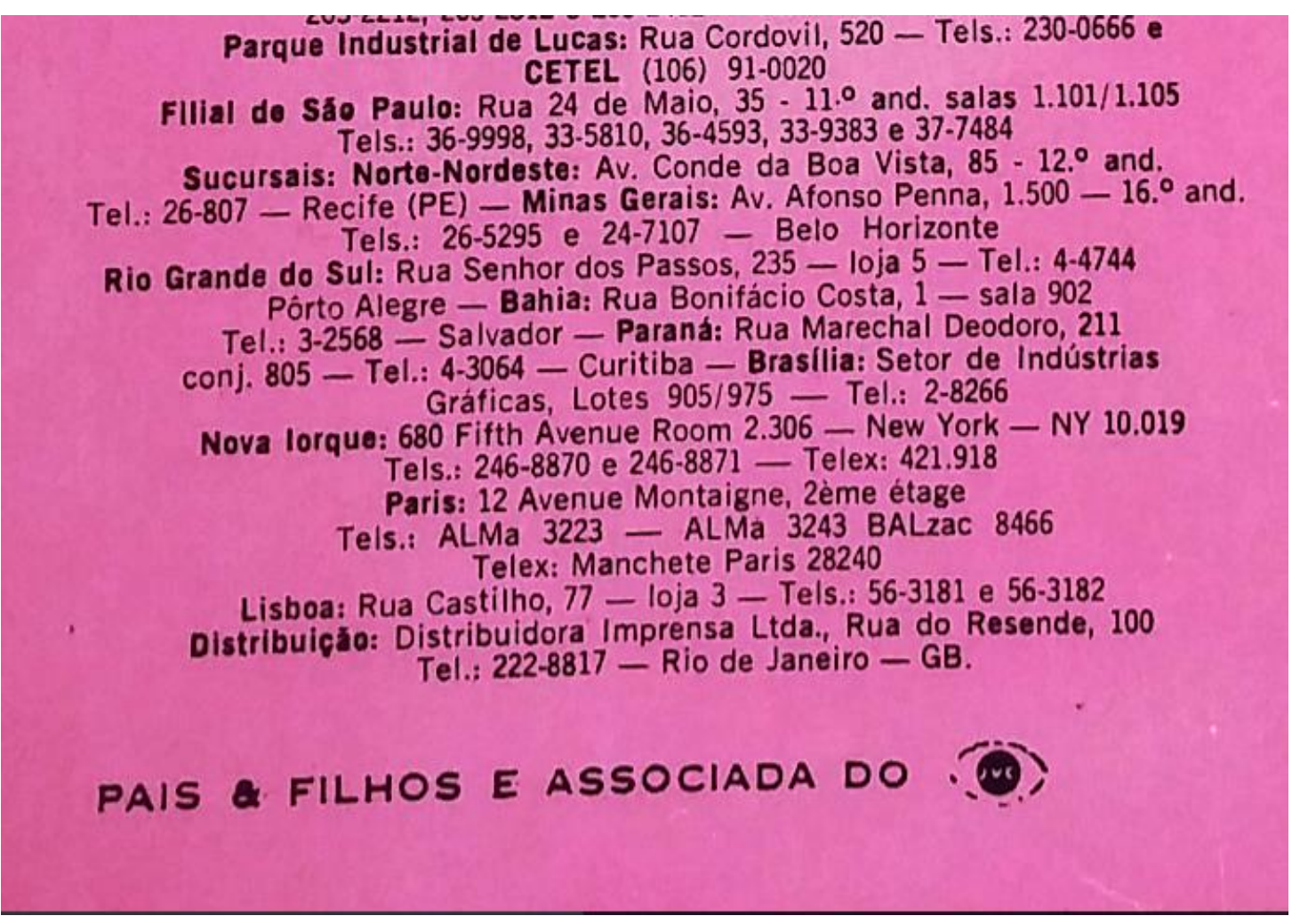


Na análise preliminar de alguns exemplares, constatou-se que Pais \& Filhos era produzida no Brasil e circulava em todo país, já que a Editora Bloch possuía escritórios em São Paulo, Minas Gerais e Rio Grande do Sul, por exemplo. Ela também parece ter circulado em outros países conforme indicam as informações sobre a distribuição da publicação em Nova Iorque, Paris, Lisboa, Milão e Tóquio.

As propagandas também merecem anotações, registradas em um banco de dados no Microsoft Excel, contando com a indicação ano, número, quantidade de páginas, valor do exemplar, produto anunciado, categoria provisória, tamanho do reclame e data da coleta dos dados. No caso de o texto da propaganda ter relação com as representações pretendidas, realiza-se a transcrição do texto e a respectiva página de publicação.

Os artigos considerados pertinentes são transcritos, mantendo-se os critérios de referências bibliográficas, como o nome do autor (caso haja menção), o título e a página. Os textos versam sobre a saúde e a educação de bebês, crianças e adolescentes. Também ganham destaque matérias direcionadas às mulheres gestantes, apresentando orientações comportamentais e médicas sobre a experiência de maternidade. Cabe ressaltar que, a partir do levantamento inicial, notou-se que os artigos trazem indicação do redator do texto, fotógrafo, o nome de um consultor especializado, seguido de sua área de atuação ${ }^{4}$.

Faz-se necessário refletir sobre a questão da autoria e da estratégia do uso de consultores apresentados na revista. Para Foucault, a noção de autor, comumente disponível na sociedade, representa "o momento crucial da individualização na história das ideias, dos conhecimentos, das literaturas, e também na história das filosofias e das ciências" (FOUCAULT, 2001, p. 267). Ele questiona: o que de fato é a obra de um dado autor? A quem se aplicaria a autoria?

No caso do impresso em questão, não se pode atribuir autoria a uma única pessoa ou ao redator do texto. Parece que este foi elaborado a

4 Pais \& Filhos possuía uma equipe de consultores em "reprodução humana, pediatria, endocrinologia, tisiologia e pneumologia, cancelorogia, foniatria, gastroenterologia, cardiologia, otorrinolaringologia, dermatologia, odontologia, ortopedia, psicologia, psicanálise, psiquiatria e primeiros socorros" (PAIS \& FILHOS, 1968, p. 131). 
partir do diálogo com os consultores especializados, listados com frequência na seção "Estes são os consultores da sua revista".

Sobre o "nome próprio" do autor, para Foucault, ele serve para caracterizar um certo modo de ser do discurso, pois o fato de haver uma "tal pessoa como autor disso", indica que esse discurso "não é uma palavra cotidiana, indiferente, uma palavra que se afasta, que flutua e passa, uma palavra imediatamente consumível, mas que se trata de uma palavra que deve ser recebida de uma certa maneira e que deve, em uma dada cultura, receber um certo status" (FOUCAULT, 2001, p. 267).

A revista possui colunas fixas, dentre as quais se destacam:

a) "Os Conselhos do Dr. De Lamare" 5 que trazia informações e dicas sobre os cuidados com os bebês, fundamentadas no campo da pediatria e da puericultura;

b) "Menu do Bebê", contendo receitas consideradas saudáveis e apropriadas para a faixa etária;

c) "Criança diz cada uma", assinada por Pedro Bloch", era um espaço dedicado à apresentação de falas e fatos infantis curiosos e engraçados observados pelo autor;

d) "Advogado da família" era uma coluna que trazia respostas às perguntas dos leitores, como questões relativas aos processos de separação, desquite e guarda dos filhos. Foi assinada nos anos iniciais por Dr. Haroldo Lins e Silva, seguido por Dr. Paulo Lins e Silva;

e) espaço de correspondência dos leitores, existente desde o início da revista, que recebeu nomes diversos, como "Pais \& Filhos escrevem", "Cartas", "Caixa Postal, P \& F responde", com a proposta de receber perguntas dos leitores sobre Psicologia, Ginecologia, Pediatria e outras áreas, com a publicação da resposta por consultores especializados7. Nessa seção, incluem-se, ainda, solicitações, como pedidos de assinaturas.

\footnotetext{
5 Rinaldo De Lamare (1910-2002) foi um importante pediatra brasileiro, colunista de Pais \& Filhos e autor do livro "A Vida do Bebê", editado até hoje. Nas edições dos anos 1970, sua seção era veiculada no formato de suplemento destacável, com cerca de oito páginas. Nos anos 1980, seus textos passaram a ocupar uma página no interior da revista e foram publicados até os anos 1990.

6 Pedro Bloch (1914-2004) era membro da família dona da editora e foi um médico foniatra, jornalista, compositor, poeta, dramaturgo e autor de diversos livros infanto-juvenis e científicos, alguns divulgados em propagandas nas páginas de Pais \& Filhos.

7 "Nas cartas dos leitores aqui respondidas, você pode encontrar solução para algum problema que esteja enfrentando: seja na educação dos filhos, na sua vida conjugal ou mesmo um pedido de infor-
} 
A leitura desta seção de Pais \& Filhos fornece aspectos interessantes a respeito do relacionamento entre seus leitores e equipe editorial. Muitos deles encaminhavam dúvidas relativas a aspectos psicológicos e médicos dos filhos (crianças ou adolescentes), como se vê no título "Receitas contra pipi na cama”, e até de si mesmos, exemplificada pelo tópico "Gravidez prolongada". Também é possível encontrar críticas, positivas e negativas, como se revela no tópico "A lombada em questão". Chamou a atenção, nessa mesma página, a solicitação apresentada no tópico "Assuntos religiosos”. Nele, o leitor questiona a ausência de participação de consultores evangélicos no que diz respeito aos assuntos teológicos, abordagem que, anteriormente, havia sido sugerida na mesma coluna por católicos de várias cidades. Cabe ressaltar que Frei Pedro Secondi (católico), doutor em Teologia, ocupou a função de consultor na década de 1970, o que permite inferir que a solicitação do leitor evangélico não foi prontamente atendida.

Tal cenário observado na dinâmica de resposta às cartas dos leitores possibilita uma articulação com as reflexões de Michel de Certeau (1998) a respeito do processo de produção discursiva e cultural, especialmente em relação aos ditos "consumidores", representados pelos leitores da revista. Se atentarmos para a potência do seu papel de intervenção nos formatos e assuntos abordados em Pais \& Filhos, pode-se compreender a relação existente, sugerida por Certeau, entre os produtores e os consumidores, pois a ideia de "informar a população", baseada em uma "pretensão pedagógica" da própria revista, não consegue captar o ato de consumir empreendido pelos sujeitos. Para Certeau, assimilar a cultura contempla um duplo movimento de tornar-se semelhante ao que se absorve e torná-lo semelhante ao que se é, tornando-o próprio, [re]apropriando-se dele. orientadas por um especialista" (Pais \& Filhos, jan. 1980, n. 5, p. 62). 
Certeau contribui, ainda, para o rompimento da concepção de leitura como atividade passiva, ao indicar que "o leitor inventa no texto outra coisa que não aquilo que era a intenção dos produtores do discurso, criando algo não-sabido no espaço organizado por sua capacidade de permitir uma pluralidade indefinida de significações" (CERTEAU, 1998, p. 265). Mas, o que os sujeitos fazem com os objetos culturais que lhes são dados a conhecer?

Figura 5 - Folheto suplementar. Fonte: Fundação Biblioteca Nacional -

Pais \& Filhos, abr. 1974, n. 8.

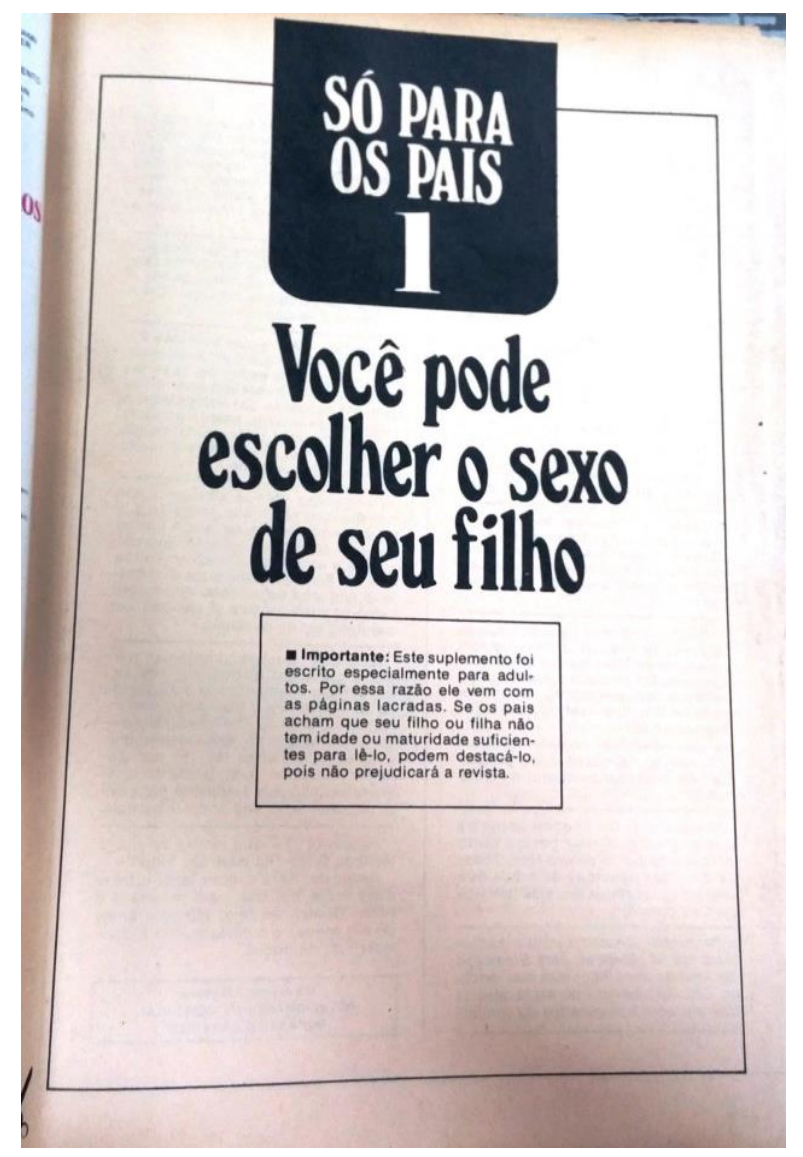

Figura 6 - Folheto suplementar. Fonte: Fundação Biblioteca Nacional Pais \& Filhos, ago. 1974, n. 12.

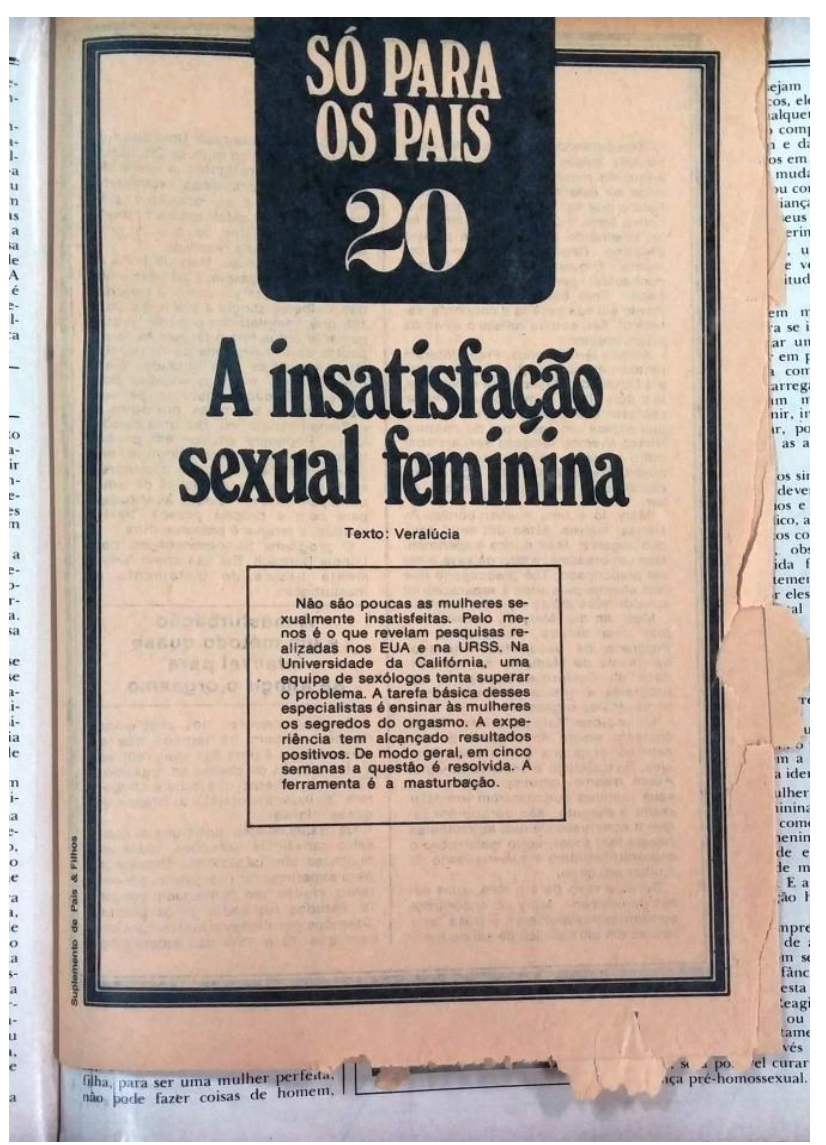

As respostas dos leitores enviadas para a coluna "Pais e Filhos escrevem" trazem indícios desses fazeres, pois apontam opiniões dos leitores, visões críticas da revista e até mesmo elogios. Tal afirmação permite percebê-los como insubmissos, capazes de sintetizar discursos, fugir da ordem, agindo entre estratégias e táticas. As primeiras pretendem se 
instituir como próprio, lugar que enuncia, que escreve e impõe determinada visão. Já os sujeitos ordinários, históricos e insubmissos, ainda que inseridos em uma ordem estratégica e disciplinar, caminham no espaço das estratégias, no que não lhe é próprio. Nesse contexto, as táticas correspondem ao espaço das astúcias e minúcias, capazes até mesmo de transformar, no caso analisado, abordagens e conteúdos de um periódico.

A publicação contava ainda com seções temáticas, disponibilizadas em suplementos fechados e destacáveis, que geralmente abordavam assuntos considerados inapropriados para menores.

Observou-se que, ainda que o público-alvo leitor fosse composto por adultos (mães, pais e profissionais das áreas de educação, por exemplo), crianças e adolescentes também teriam contato com o impresso. $\mathrm{O}$ destinatário do suplemento são os adultos, mas com a estratégia do suplemento lacrado, os pais poderiam usar seu conhecimento sobre a maturidade dos filhos para julgar apropriada ou não sua leitura, destacando o encarte, caso necessário.

\section{Considerações finais}

A investigação apresentada, cuja abordagem se aproxima do campo da história cultural, possibilitou relacionar os estudos de autores, como Marc Bloch (2001), Michel de Certeau (1998), Michel Foucault (2001) e Roger Chartier (1990;2002), com os aspectos observados a partir do investimento sobre a fonte-objeto pesquisada, a revista Pais \& Filhos. Problematizaram-se, especialmente, a materialidade e a periodização, a organização e estruturação do impresso e as questões que emanaram da leitura dos exemplares, como a dinâmica vigente na relação leitor-equipe editorial e a autoria compartilhada dos artigos.

A partir da discussão empreendida nesse trabalho, pode-se afirmar que a operação historiográfica envolve um investimento analítico sobre aspectos como a metodologia, a função e caracterização dos documentos, o papel do historiador, a postulação e revisão das questões, além da esco- 
lha, manuseio e problematização das fontes. Nessa perspectiva, este trabalho almejou favorecer a compreensão do documento histórico como espaço híbrido, no qual se articulam representações sociais, construídas por múltiplos atores, como editores, autores e os próprios leitores.

Espera-se, ainda, que a investigação em andamento contribua para o campo de produção científica que tem as representações relativas à infância e à sua educação como foco, assim como para o campo de estudos da Educação que tem a imprensa periódica como objeto de pesquisa e fonte privilegiada de acesso aos sujeitos sociais, o que permite um olhar sobre a educação conduzida em espaços para além do âmbito escolar, como é o caso de Pais \& Filhos, um espaço educativo não-formal por excelência.

\section{Referências}

BACELLAR, Carlos. Fontes documentais: uso e mau uso dos arquivos. In: PINSKI, Carla B. (Org.). Fontes históricas. São Paulo: Contexto, 2005. BICCAS, Maurilane de Souza. Roger Chartier: contribuições para a história da educação. In: LOPES, Eliane Marta Teixeira; FARIA FILHO, Luciano Mendes de (Orgs.). Pensadores sociais e História da Educação II. Belo Horizonte: Autêntica Editora, 2012, p. 269-296.

BLOCH, Marc. Apologia da História ou O Ofício do Historiador. Rio de Janeiro: Jorge Zahar Editor, 2001.

BURKE, Peter (Org.). A escrita da história: novas perspectivas. São Paulo: Editora da Universidade Estadual Paulista, 1992.

CERTEAU, Michel de. A invenção do cotidiano: artes de fazer. 3. ed. Petrópolis: Vozes, 1998.

CHARTIER, Roger. Introdução: por uma sociologia histórica das práticas culturais. In: _. A história cultural: entre práticas e representações. Lisboa: Difel; São Paulo: Bertrand Brasil, 1990.

. O mundo como representação. In: - À beira da falésia:

a história entre certezas e inquietude. Porto Alegre: Ed. UFRGS, 2002. FOUCAULT, Michel. O que é um autor. In: Ditos e Escritos - Vol. III. Rio de Janeiro: Forense Universitária, 2001. 
LE GOFF, Jacques. Documento/monumento. In: Enciclopédia Einaldi $v$. 1: Memória-história. Porto: Imprensa Nacional; Casa da Moeda, 1985, p. 95-105.

PROST, Antoine. Doze lições sobre a história. Belo Horizonte: Autêntica Editora, 2008.

\section{Fontes}

PAIS \& FILHOS. Rio de Janeiro: Bloch Editores. Fundação Biblioteca Nacional, 1968-2000.

Recebido em 27 de janeiro de 2016. Aprovado em 27 de maio de 2016. 